\title{
Study on NO Heterogeneous Reduction Mechanism under Gasification Condition
}

\author{
Xiangyong Huang, ${ }^{1,2}$ Chengbin Zhang, ${ }^{1}$ Xiaochuan $\mathrm{Li}^{2}{ }^{2}$ and Che Huang ${ }^{2}$ \\ ${ }^{1}$ Key Laboratory of Energy Thermal Conversion and Control of Ministry of Education, School of Energy and Environment, \\ Southeast University, Nanjing, Jiangsu 210096, China \\ ${ }^{2}$ School of Hydraulic, Energy and Power Engineering, Yangzhou University, Yangzhou, Jiangsu 225127, China \\ Correspondence should be addressed to Chengbin Zhang; cbzhang@seu.edu.cn
}

Received 6 May 2016; Revised 18 July 2016; Accepted 27 July 2016

Academic Editor: Rajib Paul

Copyright (C) 2016 Xiangyong Huang et al. This is an open access article distributed under the Creative Commons Attribution License, which permits unrestricted use, distribution, and reproduction in any medium, provided the original work is properly cited.

Chemisorption of NO and successive heterogeneous reduction mechanisms on the well-defined char models under carbon/char$\mathrm{CO}_{2}$ gasification condition were investigated using density functional theory at the B3LYP/6-31G (d) level of theory. The characteristics of gasification process were concluded and incorporated into the theoretical calculations by establishing three gasification char models and taking into account the presence of $\mathrm{CO}$ in ambient gas pool. The results indicate that both the configuration of char model and adsorption mode have significant influence on the NO adsorption energy. Intensive gasification surface is likely to be thermally unfavorable and the O-down mode is regarded as the most inactive approach for NO's adsorbing. Finally, NO heterogeneous reduction mechanisms on the three char models under gasification are proposed based on detailed analysis on thermodynamic data and atomic bond populations.

\section{Introduction}

Understanding the conversion mechanism of nitric oxide (NO) in combustion and coal conversion processes is the basis of controlling and reducing $\mathrm{NO}$ emission. Extensive researches have been conducted on the heterogeneous reaction between NO and char/carbonaceous surface [1-3]. The electrons/atoms/molecules involved in the reactions are microscopically small and transfer fast enough beyond the detection limits of instruments, especially at high temperature exceeding several hundred degrees Celsius. Therefore, they are hard to be directly observed in experiments, which hinders the intrinsic understanding. Quantum chemical calculations, providing a promising alternative method to obtain the mechanistic information such as geometries, energies, and vibrational frequencies for the explanation of macroscopic experimental results, have been regarded as an effective tool for removing the barriers.

A pioneering work conducted by Kyotani and Tomita [4] focused on the reaction of carbon and $\mathrm{NO}$ or $\mathrm{N}_{2} \mathrm{O}$ by using ab initio molecular orbital theory. A mechanism of $\mathrm{N}_{2}$ formation from C-NO or C- $\mathrm{N}_{2} \mathrm{O}$ reaction was proposed. Montoya et al. [3] investigated the heterogeneous pathways for the reaction $\mathrm{C}(\mathrm{N})+\mathrm{NO} \rightarrow \mathrm{N}_{2}+\mathrm{N}_{2} \mathrm{O}+\mathrm{CO}$ in the presence of $\mathrm{O}_{2}$. They found that the reaction of $\mathrm{NO}$ molecule with char yields predominantly $\mathrm{N}_{2}$ and $\mathrm{CO}$ and small amount of $\mathrm{N}_{2} \mathrm{O}$ in the presence of $\mathrm{O}_{2}$.

Recently, Jiang's team $[1,5]$ carried out a series of density functional theory (DFT) calculations to study the heterogeneous reduction between $\mathrm{NO}$ and char-bound nitrogen. NO chemisorption of direct nitrogen-nitrogen interaction and $\mathrm{N}_{2}$ desorption from medium chemisorbed surface during coal combustion were investigated based on thermodynamics and kinetics evaluation. Reaction rate of rate-limiting step involved in $\mathrm{N}_{2}$ desorption and the overall $\mathrm{NO}$ reduction rate were obtained.

These studies above opened the door a crack for a molecular-level understanding of the heterogeneous reactions between NO and char/carbon. However, the understanding of the process is still far from complete because of the complexity of gas-solid heterogeneous interaction. Most studies have focused on the conventional air-fired 
conditions and less information is available on the molecular explanation for gasification condition or combustion with high concentration of $\mathrm{CO}_{2}$. The aim of the present study is to set up molecular char models suitable for gasification condition and propose a preliminary NO heterogeneous reduction mechanism using DFT calculations.

\section{Computational Details}

2.1. Physical Model. It is widely accepted that $\mathrm{CO}_{2}$ gasification of coal char plays an important role during the coal conversion process and some combustion technologies such as oxyfuel combustion with $\mathrm{CO}_{2}$ concentration in flue gas over $60 \%$ [6]. Not only the fundamental combustion issues such as coal ignition and char burnout but also pollutant abatement issues such as nitrogen conversion are all affected by gasification reactions [7-9]. Therefore, it is essential to take into account the effects of $\mathrm{CO}_{2}$ gasification in quantum chemical calculations. In the present work, the issue is treated deliberately and the solution is implemented by establishing appropriate char models and taking into account the presence of $\mathrm{CO}$, an important product of $\mathrm{CO}_{2}$ gasification, in ambient gas pool.

Actually, the gasification process, especially the reactions of char/carbon with the oxygen-containing gases, $\mathrm{O}_{2}, \mathrm{CO}_{2}$, and $\mathrm{H}_{2} \mathrm{O}$, has been studied extensively for it is coupled in many thermal conversions processes $[10,11]$. Different gasification mechanisms have been proposed using quantum chemical calculation based on experimental observations. A common procedure comprising three brief steps is concluded as follows:

(1) An oxygen-containing gas molecule firstly is chemisorbed onto a well-defined carbon surface and covers some active sites.

(2) Oxygen atom(s) covalently bond to a carbon atom and remain on the surface while the other atoms leave from the surface after a series of elementary reactions.

(3) The C-C bonding in the parent carbon matrix is weakened by the $\mathrm{C}-\mathrm{O}$ bonding and leads to breakage. Finally, the oxygen atom(s) leave the surface in the formation of $\mathrm{CO}$ or $\mathrm{CO}_{2}$ and some active sites are created.

In the procedure, the oxygen atom's adsorption and desorption lead to the cyclic change of active sites on carbon surface, which drives the gasification reaction cycle to loop continuously. Therefore, the carbon surface with adsorbed oxygen atom(s) can be regarded as a symbolical structure in carbon/char- $\mathrm{CO}_{2}$ gasification. Moreover, the accumulation of oxygen atom on char surface will increase when the gasification reaction becomes intense due to more reactions occurring simultaneously. Based on the recognition, three char models used in this work are proposed and presented in Figure 1. Each model is characterized by the attachment of $\mathrm{O}$ atom(s) to a conventional char model in zigzag configuration (five six-membered benzene rings). The number of oxygen atoms is an indicator of gasification condition; that is, one, two, and three preadsorbed $\mathrm{O}$ atom(s) correspond to mild gasification, moderate gasification, and intensive gasification, respectively.

The conventional char model in zigzag configuration with five six-membered benzene rings is chosen as a main frame here due to the following merits:

(1) The model possesses good physical reality and its size and configuration are in accordance with experimental observation [11].

(2) The suitable size of the model not only is large enough to minimize edge effects but also gives a reasonable tradeoff between accuracy and computational cost.

2.2. Chemical Method. All calculations were conducted at the B3LYP DFT level of theory with the 6-31G(d) basis set. This method is recognized to produce fairly accurate bond energies, thermodynamic data, and reasonably small spin contamination $[12,13]$. It has been proved to be rational to apply the method to polyaromatic molecules by a lot of previous work $[4,11]$. The spin multiplicity of each structure was determined with the typical procedure as that described in literature [4]. Single point energy calculations at several electronic states are performed and the one giving the lowest energy is determined as the electronic ground state. The default convergence criteria embedded in Gaussian (maximum force, <0.000450; RMS (root-mean-square) force, $<0.000300$; maximum displacement, <0.001800; and RMS displacement, $<0.001200$, all the values in atomic units) were used in geometry optimization.

The heat of reaction, denoted by $\Delta H$, is defined as a difference between the total energies of the optimized products and the sum of the energies of the corresponding reactants. The possible paths of NO heterogeneous reduction over gasification char surface have been evaluated according to the thermal parameters and bonding strengths of the species involved in the process. All calculations were carried out using the Gaussian 09 package [14].

\section{Results and Discussion}

3.1. Chemisorption of NO on the Char Models. Chemisorption is crucial in many cases for a reaction because it initiates the subsequent reactions. And thus, the configuration of the reaction system is largely determined by chemisorption process. Theoretical calculations on $\mathrm{NO}$ adsorption on the three char models were made to obtain the characteristics of NO adsorption on the char models. The typical adsorption modes used in this work are shown in Figure 2.

As seen from Figure 3, it could be concluded that both the configuration of char model and adsorption mode have significant influence on the NO adsorption energy obtained from frequency calculation. The adsorption energy varies dramatically with different char models. For side-on mode and vertical-N-down mode, the energy value decreases roughly as the number of preadsorbed $\mathrm{O}$ atoms increases with the same adsorption mode; that is, the adsorption energy is generally ranked in a descending order for certain adsorption mode: $\Delta H_{\mathrm{ad}, \mathrm{M} 0}>\Delta H_{\mathrm{ad}, \mathrm{M} 1}>\Delta H_{\mathrm{ad}, \mathrm{M} 2}>\Delta H_{\mathrm{ad}, \mathrm{M} 3}$. But the $\mathrm{O}$-down mode does not satisfy the principle. However, it is 


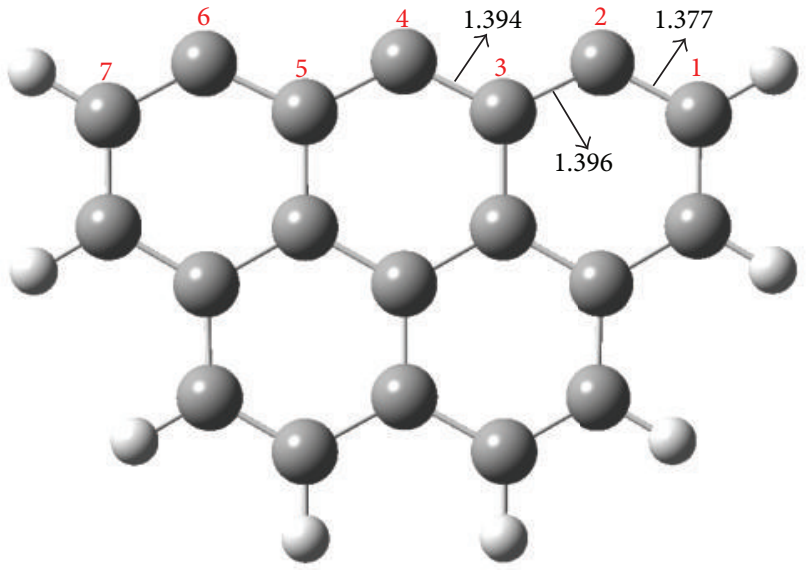

(a) M0 (fresh char model)

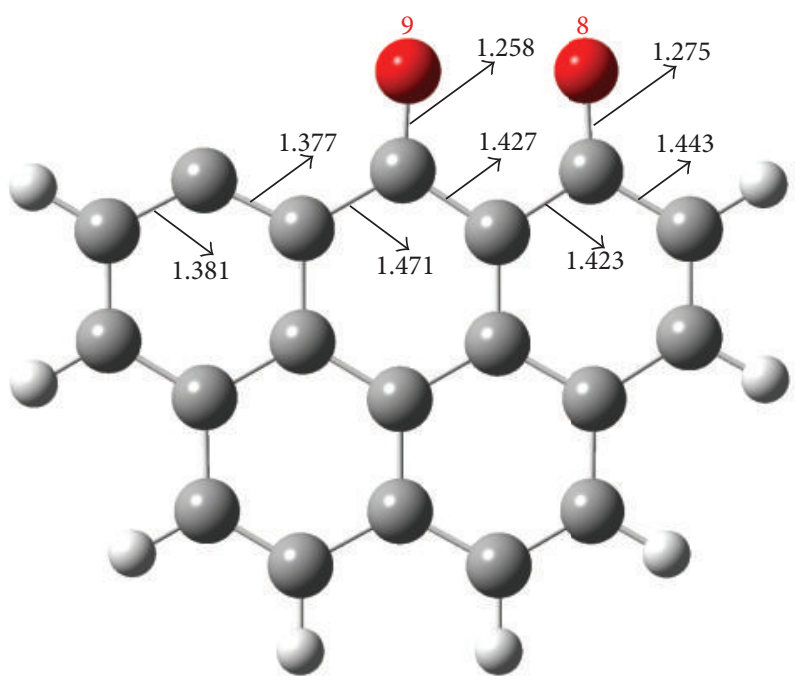

(c) M2 (moderate gasification)

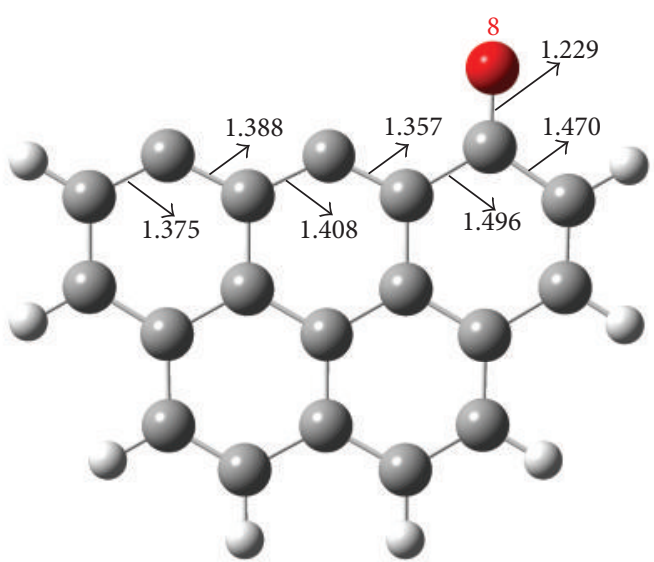

(b) M1 (mild gasification)

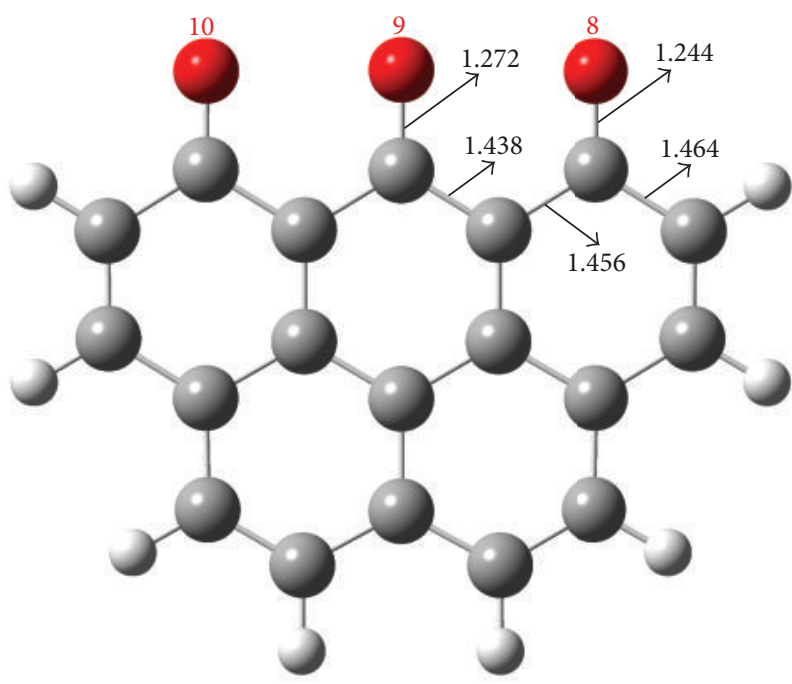

(d) M3 (intensive gasification)

FIgURE 1: Char models in gasification (bond lengths are given in angstroms. The numerical order of the first $\mathrm{C}$ layer in other species is the same as that in $\mathrm{M} 0$ ).

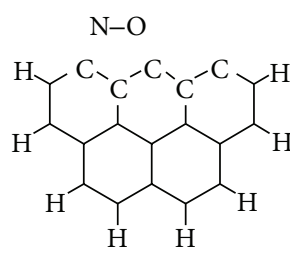

Side-on

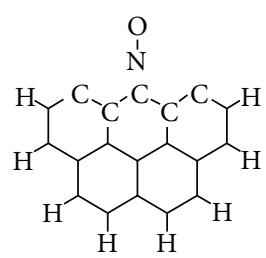

Vertical-N-down

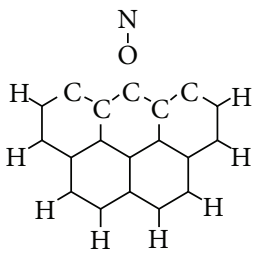

Vertical-O-down

Figure 2: Schematic diagram of side-on, N-down, and O-down modes for NO adsorption.

deduced that the char surface where gasification reactions are taking place is not favorable to the NO adsorption. Actually, the adsorption energies are all close to zero for all modes with the M3 model, which means that it is difficult for $\mathrm{NO}$ to bond well with the intensive gasification surface or NO can only physically adsorb on the surface. Hence, the conclusion may have negative impact on the follow-up NO

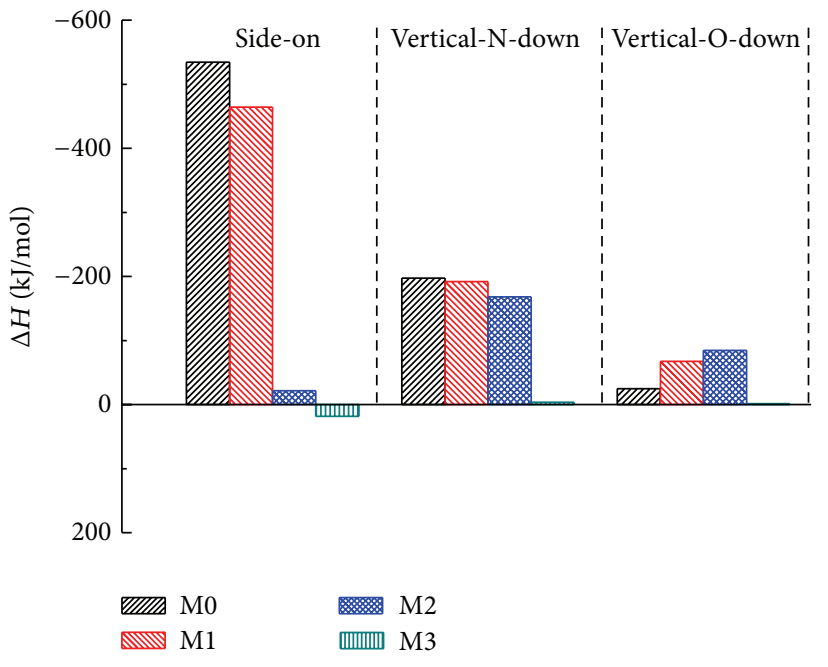

FIGURE 3: Adsorption heat of NO on char surface under gasification condition. 
heterogeneous reduction on coal char. Fortunately, there still exist several positive factors: (1) the gasification reactions proceed with carbon- $\mathrm{CO}_{2}$ interaction cycles involving a dynamic balance of active sites. The balance is implemented by the consumption by small gaseous molecules' adsorption and the generation by surface complex's leaving the matrix with bond cleavage. Therefore, in practical application, there remain active sites for $\mathrm{NO}$ to be adsorbed even for intensive gasification condition; (2) the $\mathrm{CO}$ concentration near the char surface is rather great due to the accumulation resulting from limited $\mathrm{CO}$ diffusion rate and high $\mathrm{CO}$ generation rate. As a consequence, the oxygen is consumed by the remaining $\mathrm{CO}$ and the oxidation of nitrogen-containing is inhibited. Moreover, the presence of $\mathrm{CO}$ increases the reducibility of the atmosphere, which is benefit for both homogeneous and heterogeneous reduction of $\mathrm{NO}_{x}$.

The adsorption modes have great influence on the magnitudes of the energy value. It is clearly indicated that, for the M0 and M1 models, the values magnitudes are ranked in a descending order: $\Delta H_{\text {ad,side-on }}(\sim 500 \mathrm{~kJ} / \mathrm{mol})>$ $\Delta H_{\text {ad,N-down }}(\sim 200 \mathrm{~kJ} / \mathrm{mol})>\Delta H_{\text {ad,O-down }}(\leq 100 \mathrm{~kJ} / \mathrm{mol})$. However, it is not suitable for M2 and M3 models. It can be briefly concluded that, for the M0 and M1 models, the sideon mode can obtain the most stable structure while for the M2 model the $\mathrm{N}$-down mode is the most stable way to be adsorbed.

Moreover, the adsorption modes differ in the sensitivity to the char models. For side-on mode, significant difference can be found in the adsorption energies with different char models while the other two modes seem less sensitive to the variation of char models, although their values are relatively small. It should be noted that the heat values of vertical-Odown mode with different char models are generally low and it can be regarded as the most inactive approach for $\mathrm{NO}$ to be adsorbed.

3.2. NO Heterogeneous Reduction Mechanism on the M2 Char Model. DFT calculations were conducted and the optimized structures discussed below are drawn in Figure 4 and the optimized parameters for the selected bonds of the structures involved in the NO heterogeneous reduction pathways are listed in Table 1. Some atoms of the species are numbered to facilitate the following discussions. For simplicity, NO heterogeneous reduction mechanism on the M2 char model is sometimes abbreviated to M2 pathway, and it is similar for the cases of the M1 char model and the M3 char model.

NO heterogeneous reduction process is initiated by its chemisorption on char surface. It has been identified $\mathrm{N}$-down mode is the most stable chemisorption way for $\mathrm{NO}$ on model M2 and an intermediate, structure IM1, is generated by the chemisorption process with a transition state as depicted in Figure 5.

It can be seen that the $\mathrm{N}(10)-\mathrm{O}(11)$ bond in IM1 exhibits a relatively weak bonding with a Milliken bond population of 0.184 which is lower significantly than that of other bonds. It is further reduced to 0.012 in IM2 and the corresponding bond length increases from $1.221 \AA$ to $1.423 \AA$ after a CO molecule's adsorption on IM1. And then the bond becomes weak enough
TABLE 1: Optimized parameters for the selected bonds of the structures involved in the NO heterogeneous reduction pathways.

\begin{tabular}{|c|c|c|c|}
\hline Species & Bond & Length $(\AA)$ & Population \\
\hline \multirow{4}{*}{ IM1 } & $\mathrm{C}(2)-\mathrm{O}(8)$ & 1.277 & 0.387 \\
\hline & $\mathrm{C}(4)-\mathrm{O} 9$ & 1.263 & 0.453 \\
\hline & $\mathrm{C}(6)-\mathrm{N}(10)$ & 1.358 & 0.261 \\
\hline & $\mathrm{N}(10)-\mathrm{O}(11)$ & 1.221 & 0.184 \\
\hline \multirow{6}{*}{ IM2 } & $\mathrm{C}(2)-\mathrm{O}(8)$ & 1.269 & 0.405 \\
\hline & $\mathrm{C}(4)-\mathrm{O} 9$ & 1.267 & 0.420 \\
\hline & $\mathrm{C}(6)-\mathrm{N}(10)$ & 1.340 & 0.342 \\
\hline & $\mathrm{N}(10)-\mathrm{O}(11)$ & 1.423 & 0.012 \\
\hline & $\mathrm{O}(11)-\mathrm{C}(12)$ & 1.333 & 0.159 \\
\hline & $\mathrm{C}(12)-\mathrm{O}(13)$ & 1.189 & 0.491 \\
\hline \multirow{4}{*}{ IM3 } & $\mathrm{C}(2)-\mathrm{O}(8)$ & 1.238 & 0.555 \\
\hline & $\mathrm{C}(4)-\mathrm{O} 9$ & 1.359 & 0.192 \\
\hline & O9-N(10) & 1.430 & 0.144 \\
\hline & $\mathrm{N}(10)-\mathrm{C}(6)$ & 1.336 & 0.299 \\
\hline \multirow{6}{*}{ IM4 } & $\mathrm{C}(2)-\mathrm{O}(8)$ & 1.233 & 0.548 \\
\hline & $\mathrm{C}(4)-\mathrm{O} 9$ & 1.340 & 0.309 \\
\hline & $\mathrm{C}(6)-\mathrm{N}(10)$ & 1.321 & 0.387 \\
\hline & O9-C(11) & 1.437 & 0.206 \\
\hline & $\mathrm{C}(11)-\mathrm{N}(10)$ & 1.377 & 0.331 \\
\hline & $\mathrm{C}(11)-\mathrm{O}(12)$ & 1.201 & 0.622 \\
\hline \multirow{5}{*}{ IM4-1 } & $\mathrm{C}(2)-\mathrm{O}(8)$ & 1.233 & 0.580 \\
\hline & $\mathrm{C}(4)-\mathrm{O} 9$ & 1.372 & 0.207 \\
\hline & $\mathrm{C}(6)-\mathrm{N}(10)$ & 1.398 & 0.026 \\
\hline & $\mathrm{N}(10)-\mathrm{N}(11)$ & 1.339 & 0.035 \\
\hline & $\mathrm{N}(11)-\mathrm{O}(12)$ & 1.214 & 0.287 \\
\hline \multirow{5}{*}{ IM4-2 } & $\mathrm{C}(2)-\mathrm{O}(8)$ & 1.274 & 0.398 \\
\hline & $\mathrm{C}(4)-\mathrm{O} 9$ & 1.260 & 0.451 \\
\hline & $\mathrm{C}(6)-\mathrm{N}(10)$ & 1.381 & 0.306 \\
\hline & $\mathrm{N}(10)-\mathrm{C}(11)$ & 1.207 & 0.548 \\
\hline & $\mathrm{C}(11)-\mathrm{O}(12)$ & 1.177 & 0.592 \\
\hline \multirow{5}{*}{ IM4-3 } & $\mathrm{C}(2)-\mathrm{O}(8)$ & 1.232 & 0.571 \\
\hline & $\mathrm{C}(6)-\mathrm{N} 9$ & 1.297 & 0.418 \\
\hline & $\mathrm{C}(11)-\mathrm{N} 9$ & 3.018 & 0.012 \\
\hline & $\mathrm{C}(11)-\mathrm{O}(12)$ & 1.167 & 0.587 \\
\hline & $\mathrm{C}(11)-\mathrm{O}(10)$ & 1.171 & 0.562 \\
\hline \multirow{8}{*}{ IM5 } & $\mathrm{C}(1)-\mathrm{C}(2)$ & 1.468 & 0.362 \\
\hline & $C(2)-C(3)$ & 1.489 & 0.196 \\
\hline & $C(3)-C(4)$ & 1.373 & 0.338 \\
\hline & $C(4)-C(5)$ & 1.387 & 0.302 \\
\hline & $C(5)-C(6)$ & 1.465 & 0.278 \\
\hline & $C(6)-C(7)$ & 1.454 & 0.340 \\
\hline & $\mathrm{C}(2)-\mathrm{O}(8)$ & 1.232 & 0.572 \\
\hline & $\mathrm{C}(6)-\mathrm{N}(9)$ & 1.297 & 0.445 \\
\hline \multirow{4}{*}{ IM6 } & $\mathrm{C}(2)-\mathrm{O}(8)$ & 1.243 & 0.512 \\
\hline & $\mathrm{C}(4)-\mathrm{O}(9)$ & 1.241 & 0.560 \\
\hline & $\mathrm{C}(6)-\mathrm{N}(10)$ & 1.339 & 0.182 \\
\hline & $\mathrm{N}(10)-\mathrm{N}(11)$ & 1.146 & 0.542 \\
\hline
\end{tabular}


TABLE 1: Continued.

\begin{tabular}{|c|c|c|c|}
\hline Species & Bond & Length $(\AA)$ & Population \\
\hline \multirow{4}{*}{ IM7 } & $\mathrm{C}(2)-\mathrm{O}(8)$ & 1.357 & 0.194 \\
\hline & $\mathrm{C}(4)-\mathrm{N}(9)$ & 1.362 & 0.108 \\
\hline & $\mathrm{C}(6)-\mathrm{N}(10)$ & 1.301 & 0.436 \\
\hline & $\mathrm{N}(9)-\mathrm{O}(11)$ & 1.214 & 0.283 \\
\hline \multirow{7}{*}{ IM8 } & $\mathrm{C}(2)-\mathrm{O}(8)$ & 1.382 & 0.164 \\
\hline & $\mathrm{C}(4)-\mathrm{N}(9)$ & 1.377 & 0.085 \\
\hline & $\mathrm{C}(6)-\mathrm{N}(10)$ & 1.280 & 0.512 \\
\hline & $\mathrm{N}(9)-\mathrm{O}(11)$ & 1.426 & 0.033 \\
\hline & $\mathrm{O}(8)-\mathrm{N}(9)$ & 1.423 & 0.130 \\
\hline & $\mathrm{O}(11)-\mathrm{C}(12)$ & 1.321 & 0.156 \\
\hline & $\mathrm{C}(12)-\mathrm{O}(13)$ & 1.187 & 0.491 \\
\hline \multirow{4}{*}{ IM9 } & $\mathrm{C}(2)-\mathrm{O}(8)$ & 1.360 & 0.178 \\
\hline & $\mathrm{N}(9)-\mathrm{O}(8)$ & 1.435 & 0.125 \\
\hline & $\mathrm{C}(4)-\mathrm{N}(9)$ & 1.330 & 0.342 \\
\hline & $\mathrm{C}(6)-\mathrm{N}(10)$ & 1.311 & 0.002 \\
\hline \multirow{4}{*}{ IM10 } & $\mathrm{C}(2)-\mathrm{O}(8)$ & 1.225 & 0.558 \\
\hline & $\mathrm{C}(4)-\mathrm{N}(9)$ & 1.449 & 0.225 \\
\hline & $\mathrm{N}(9)-\mathrm{N}(10)$ & 1.285 & 0.300 \\
\hline & $\mathrm{C}(6)-\mathrm{N}(10)$ & 1.441 & 0.174 \\
\hline \multirow{3}{*}{ IM11 } & $\mathrm{C}(2)-\mathrm{O}(9)$ & 1.247 & 0.533 \\
\hline & $\mathrm{C}(4)-\mathrm{N}(9)$ & 1.340 & 0.190 \\
\hline & $\mathrm{N}(9)-\mathrm{N}(10)$ & 1.139 & 0.562 \\
\hline \multirow{6}{*}{ IM12 } & $\mathrm{C}(2)-\mathrm{O}(8)$ & 1.229 & 0.570 \\
\hline & $\mathrm{C}(4)-\mathrm{O}(9)$ & 1.375 & 0.255 \\
\hline & $\mathrm{C}(6)-\mathrm{O}(10)$ & 1.377 & 0.218 \\
\hline & $\mathrm{C}(11)-\mathrm{O}(9)$ & 1.366 & 0.263 \\
\hline & $\mathrm{C}(11)-\mathrm{O}(10)$ & 1.368 & 0.259 \\
\hline & $\mathrm{C}(11)-\mathrm{O}(12)$ & 1.191 & 0.648 \\
\hline
\end{tabular}

to be easily ruptured. The thermodynamic calculation also shows that the breakage of the $\mathrm{N}$-O bond is highly exothermic with $\sim 400 \mathrm{~kJ} / \mathrm{mol}$ accompanying with the release of a $\mathrm{CO}_{2}$ molecule and the formation of an intermediate, IM3.

Structure IM3 plays an important role in the NO heterogeneous reduction because it not only introduces several different successive pathways after its interaction with $\mathrm{CO}$ and $\mathrm{NO}$ but also is a shared intermediate by M2 pathway and M3 pathway (see Figure 7). The N(10)-O(9) bond is found to be a tender point, and three different stable structures, IM4, IM4-1, and IM4-2, are obtained from further NO or $\mathrm{CO}$ adsorption on the active sites around the bond. IM4 seems to be the prime product among them from a thermodynamic view. The reaction channel that a $\mathrm{CO}$ molecule adsorbs onto IM3 with a $\mathrm{C}$ atom joining with $\mathrm{N}(10)$ and $\mathrm{O}(9)$ can result in the greatest $\Delta H(\sim 200 \mathrm{~kJ} / \mathrm{mol})$ while those of the other two channels are only $140 \mathrm{~kJ} / \mathrm{mol}$ and $23 \mathrm{~kJ} / \mathrm{mol}$. Therefore, the IM3 + CO $\rightarrow$ IM4 channel is more energetically favorable. However, further analysis on the atomic bond population shows that the newly formed $\mathrm{C}(11)-\mathrm{O}(9)$ bond owns the smallest bond population in the structure. Calculations indicated the cleavage of the bond leads to the formation of IM4-2 in which $\mathrm{N}$ atom is eventually released as NCO in a strongly endothermic reaction with heat absorbed of $438.2 \mathrm{~kJ} / \mathrm{mol}$. However, the reaction channel is not presented in the schematic diagram of NO heterogeneous reduction mechanism for its final product is not the expected $\mathrm{N}_{2}$ molecule. And thus, the $\mathrm{C}(4)-\mathrm{O}(9)$ bond with the second smallest bond population is considered to examine the possibility. An intermediate IM4-3 is obtained from the presumed ring opening at the $\mathrm{C}(4)-\mathrm{O}(9)$ bond. The calculation results indicated that the $\mathrm{N}(9)-\mathrm{C}(11)$ bond in the structure IM4-3 becomes very fragile with a bond population of only 0.010 . Eventually, a $\mathrm{CO}_{2}$ molecule escapes from the parent matrix and the left part is fully optimized to a stable structure IM5.

An active site is exposed at the unsaturated C(4) atom in IM5, which makes the intermediate a chemically active species. NO is expected to adhere to the $\mathrm{C}(4)$ atom to produce only two configurations, IM6 and IM7, when NO approaches toward the structure IM5 in either side-on or vertical-Ndown/O-down mode. Each intermediate leads an individual reaction channel starting from IM5. And then, it is easily found the weakest bond of the structure IM6 exists between $\mathrm{N}(10)$ and $\mathrm{C}(6)$ while a strong bond exists between $\mathrm{N}(11)$ and $\mathrm{N}(10)$. And thus, the group of $\mathrm{N}(11)-\mathrm{N}(10)$ shows an intensive tendency to be detached from the parent structure and leaves as a $\mathrm{N}_{2}$ molecule. This is supported by a thermodynamic analysis. Only a little external heat $(\sim 1.24 \mathrm{~kJ} / \mathrm{mol})$ is needed to drive the decomposition reaction IM6 $\rightarrow \mathrm{M} 2+\mathrm{N}_{2}$ to complete the M2 pathway.

It is slightly more complicated for IM7 channel. The $\mathrm{N}(9)$ $\mathrm{C}(4)$ bond, $\mathrm{O}(8)-\mathrm{C}(2)$ bond, and $\mathrm{N}(9)-\mathrm{O}(11)$ bond are all weakened by the $\mathrm{CO}$ adsorption on $\mathrm{O}(11)$. Their bond populations decreased by different degrees during the reaction $\mathrm{IM} 7+\mathrm{CO} \rightarrow \mathrm{IM} 8$, especially for the $\mathrm{N}(9)-\mathrm{O}(11)$ bond whose bond population drops from 0.283 to the minimal number of the structure, 0.033 . Consequently, the bond becomes most likely to be cracked. The successive decomposition reaction IM8 $\rightarrow$ IM9 $+\mathrm{CO}_{2}$ proceeds as expected and a large amount of heat $(465.19 \mathrm{~kJ} / \mathrm{mol})$ is released at the same time. Afterward, two steps of configuration rearrangement, IM9 $\rightarrow$ IM10 $\rightarrow$ IM11, are found to occur with $\Delta H$ of 306.59 and -384.00 , respectively. Finally, the bonded $\mathrm{N}$ atoms leave the aromatic rings as a $\mathrm{N}_{2}$ molecule due to the weakness of the $\mathrm{N}(9)-\mathrm{C}(4)$ bond in IM11, which terminates the M2 pathway with M1. The whole M2 pathway is schematically depicted in Figure 6 with the species and energies involved in the steps.

3.3. NO Heterogeneous Reduction Mechanisms on M1 and M3 Model. It is found that a significant number of reaction steps in the M1 and M3 pathways duplicate the existing ones in the M2 pathway which has been discussed in detail previously. For simplicity, only the differences are presented in Figure 7 and analyzed here.

As regards the M1 pathway, the side-on mode has been known to generate the most stable chemisorbed species, IM3, when NO interacts with M1 model. The energy barrier of the reaction is only $86.64 \mathrm{~kJ} / \mathrm{mol}$ and seems to be passed over easily. The corresponding transition state is shown in Figure 8. 


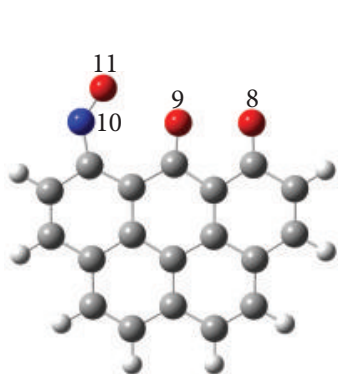

IM1

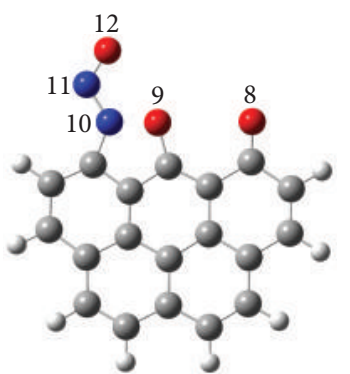

IM4-1

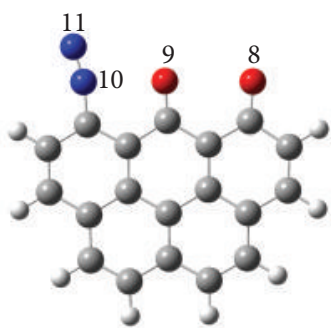

IM6

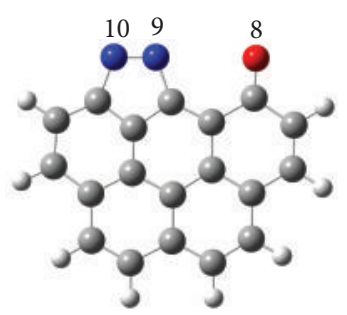

IM10
13

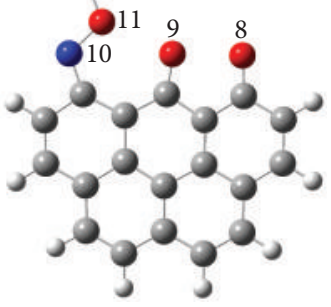

IM2

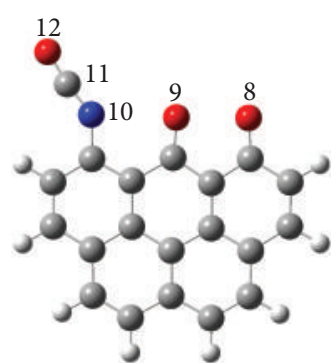

IM4-2

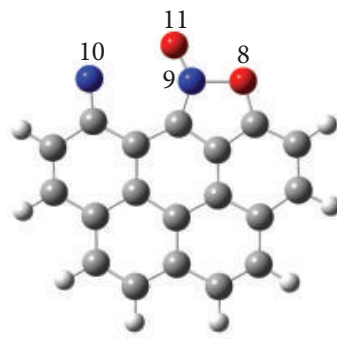

IM7

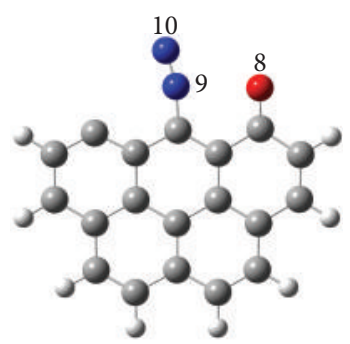

IM11

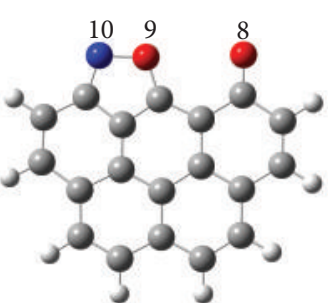

IM3

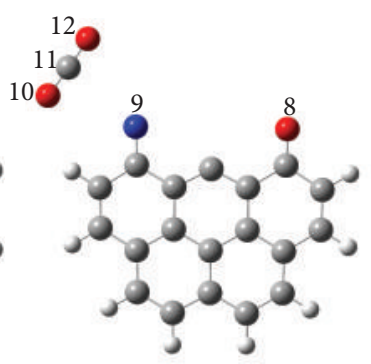

IM4-3

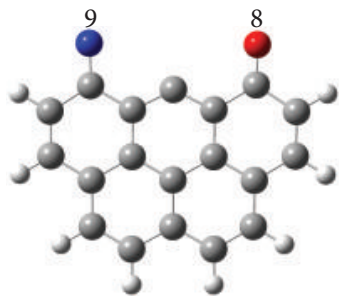

IM5

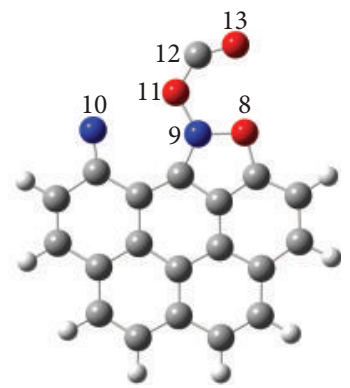

IM8

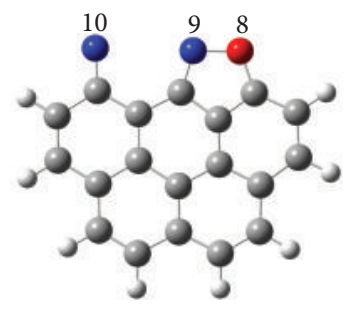

IM9

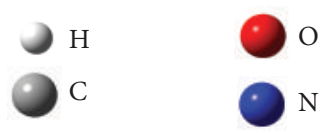

FIGURE 4: Optimized structures of stable intermediates involved in NO heterogeneous reduction. The numerical order of the first $\mathrm{C}$ layer in other species is the same as that in M0.

The reaction is thermally favorable with $464.13 \mathrm{~kJ} / \mathrm{mol}$, which increases the possibility for NO reduction to take place along this path. As for the M3 pathway, it is reasonable to take $\mathrm{CO}$ chemisorption onto M3 as an initial step, considering that it is difficult for M3 to adsorb NO stably but can easily capture $\mathrm{CO}$. The $\mathrm{CO}$ adsorption seems to have a greater influence on the side $\mathrm{C}-\mathrm{O}$ bond $(\mathrm{C}(6)-\mathrm{O}(10))$ than that on the middle one $(\mathrm{C}(4)-\mathrm{O}(9))$. The $\mathrm{C}(6)-\mathrm{O}(10)$ bond with a bond population of 0.504 is stronger than the $\mathrm{C}(4)-\mathrm{O}(9)$ bond with 0.408 in M3 model. However, the former turns out to 


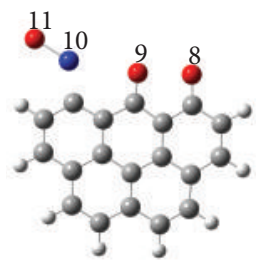

Reactant $(\mathrm{M} 2+\mathrm{NO})$

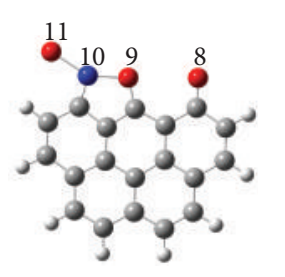

Transition state

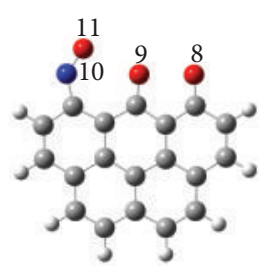

IM1

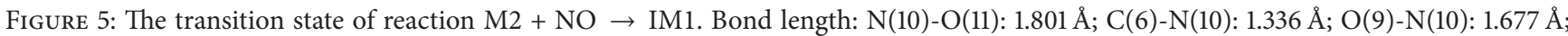
$\mathrm{C}(4)-\mathrm{O}(9): 1.315 \AA$; and $\mathrm{C}(2)-\mathrm{O}(8): 1.238 \AA$.

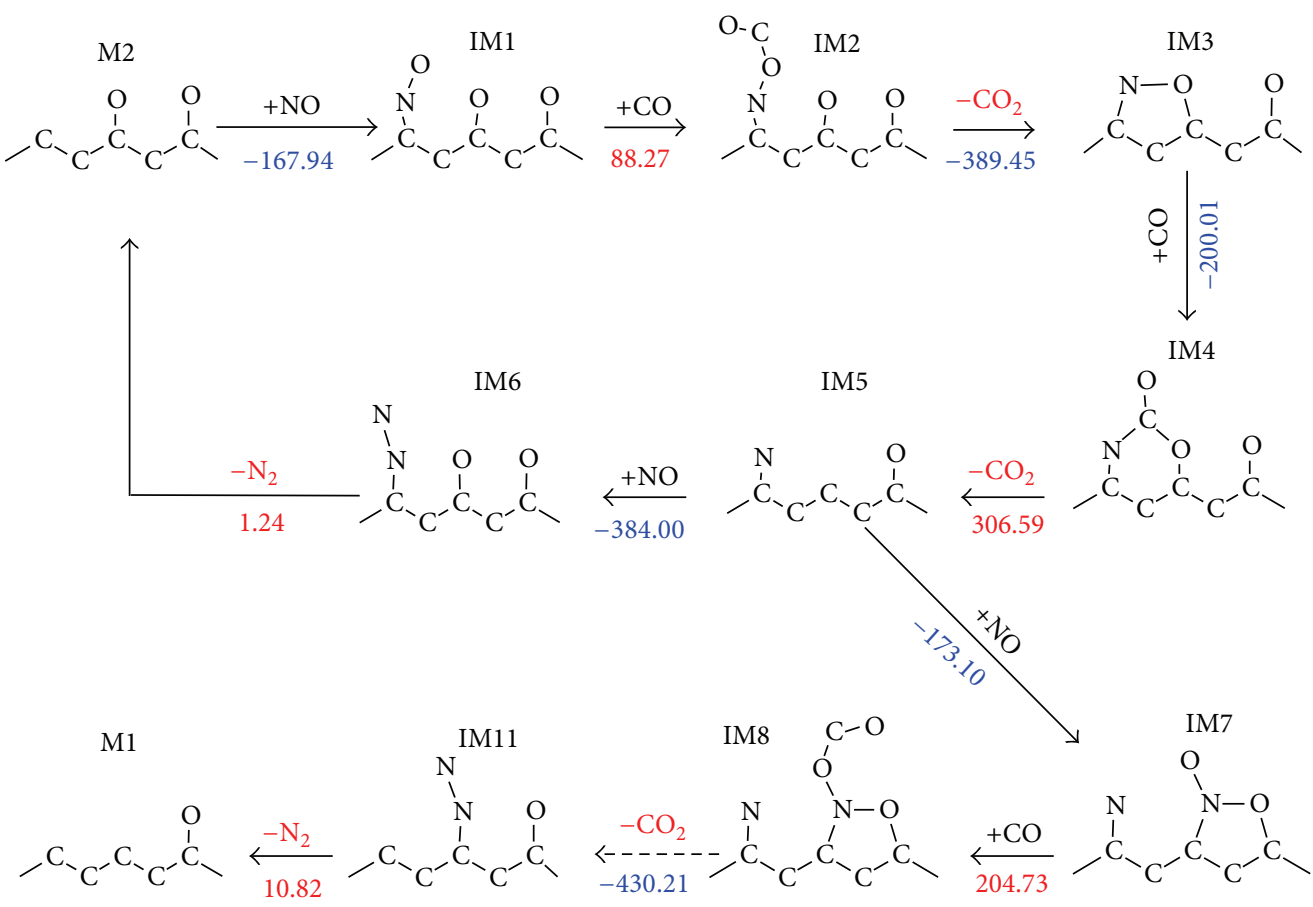

FIgURE 6: Pathways of NO heterogeneous reduction on M2 under gasification condition.
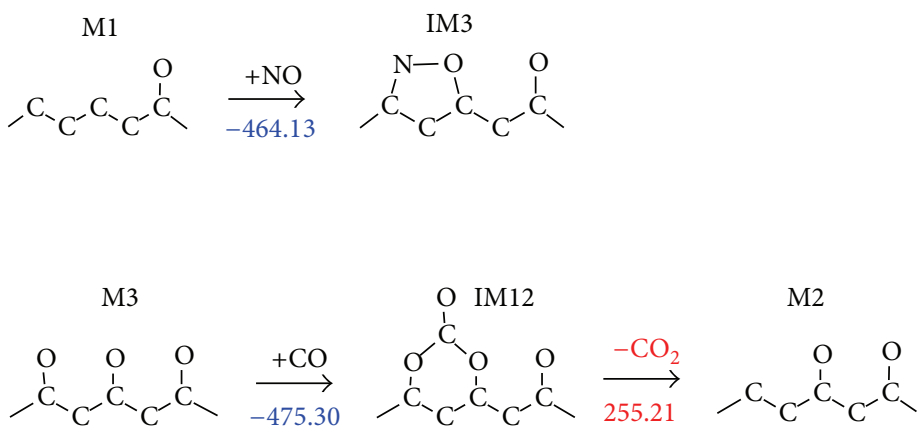

FIgURE 7: The first step(s) of NO heterogeneous reduction on M1 and M3 models. 


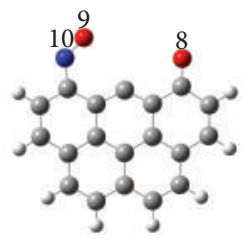

Reactant $(\mathrm{M} 1+\mathrm{NO})$

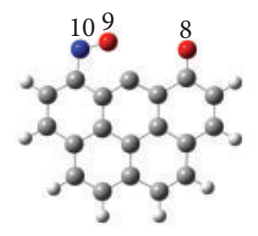

Transition state

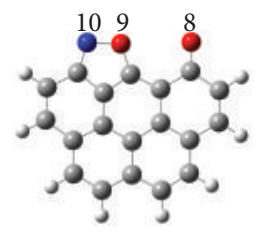

IM3
FIgURE 8: The transition state of reaction $\mathrm{M} 1+\mathrm{NO} \rightarrow \mathrm{IM} 3$. Bond length: $\mathrm{N}(10)-\mathrm{O}(9): 1.224 \AA$; $\mathrm{N}(10)-\mathrm{C}(6): 1.348 \AA$; O(9)-C(4): $2.925 \AA$; and C(2)-O(8): $1.231 \AA$.

be weaker with a bond population of 0.218 than the latter with 0.255 after the $\mathrm{CO}$ adsorption. As a result, the $\mathrm{C}(6)$ $\mathrm{O}(10)$ bond breaking occurs due to the lowest population in IM12. Afterward, the $\mathrm{C}(11)-\mathrm{O}(9)$ bond shows its weakness and is subjected to a cleavage. Finally a $\mathrm{CO}_{2}$ molecule is released and the transformation of IM12 to M2 takes place.

\section{Conclusions}

Attempts have been made in the present study to investigate NO heterogeneous reduction on char surface under gasification by using DFT calculations. On the basis of the data acquired from our calculations, the following conclusions are drawn:

(1) The characteristics of gasification reactions are analyzed in detail and implemented in our theoretical calculation by designing a conventional char model with preadsorbed $\mathrm{O}$ atom as gasification and considering the presence of $\mathrm{CO}$ in every reaction step.

(2) Both the configuration of char model and adsorption mode were found to have significant influence on the NO adsorption energy. For side-on mode and vertical-N-down mode, the energy value decreases roughly as the number of preadsorbed $\mathrm{O}$ atoms increases. For the M0 and M1 models, the side-on mode can obtain the most stable structure while for the M2 model the $\mathrm{N}$-down mode is the most stable way for adsorption.

(3) A significant number of reaction steps in the M1, M2, and M3 pathways are repetitive. The pathways for NO heterogeneous reduction on the char models under gasification are proposed based on the detailed analysis on thermodynamic energy and bonding strength.

\section{Competing Interests}

The authors declare that they have no competing interests.

\section{Acknowledgments}

The authors gratefully acknowledge the financial supports by the National Natural Science Foundation of China (Project no. 51306158), Natural Science Foundation of Jiangsu
Province (no. BK20130621), and China Postdoctoral Science Foundation (no. 2015T80478 and no. 2014M561551).

\section{References}

[1] H. Zhang, J. Liu, J. Shen, and X. Jiang, “Thermodynamic and kinetic evaluation of the reaction between $\mathrm{NO}$ (nitric oxide) and char(N) (char bound nitrogen) in coal combustion," Energy, vol. 82, pp. 312-321, 2015.

[2] A. M. Oyarzún, L. R. Radovic, and T. Kyotani, "An update on the mechanism of the graphene-NO reaction," Carbon, vol. 86, pp. 58-68, 2015.

[3] A. Montoya, T. N. Truong, and A. F. Sarofim, "Application of density functional theory to the study of the reaction of NO with char-bound nitrogen during combustion," Journal of Physical Chemistry A, vol. 104, no. 36, pp. 8409-8417, 2000.

[4] T. Kyotani and A. Tomita, "Analysis of the reaction of carbon with $\mathrm{NO} / \mathrm{N}_{2} \mathrm{O}$ using $\mathrm{Ab}$ initio molecular orbital theory," Journal of Physical Chemistry B, vol. 103, no. 17, pp. 3434-3441, 1999.

[5] H. Zhang, X. M. Jiang, J. X. Liu, and J. Shen, "New insights into the heterogeneous reduction reaction between NO and charbound nitrogen," Industrial \& Engineering Chemistry Research, vol. 53, no. 15, pp. 6307-6315, 2014.

[6] B. J. P. Buhre, L. K. Elliott, C. D. Sheng, R. P. Gupta, and T. F. Wall, "Oxy-fuel combustion technology for coal-fired power generation," Progress in Energy and Combustion Science, vol. 31, no. 4, pp. 283-307, 2005.

[7] A. Molina and C. R. Shaddix, "Ignition and devolatilization of pulverized bituminous coal particles during oxygen/carbon dioxide coal combustion," Proceedings of the Combustion Institute, vol. 31, no. 2, pp. 1905-1912, 2007.

[8] T. Suda, K. Masuko, J. Sato, A. Yamamoto, and K. Okazaki, "Effect of carbon dioxide on flame propagation of pulverized coal clouds in $\mathrm{CO}_{2} / \mathrm{O}_{2}$ combustion," Fuel, vol. 86, no. 12-13, pp. 2008-2015, 2007.

[9] H. Liu, R. Zailani, and B. M. Gibbs, "Comparisons of pulverized coal combustion in air and in mixtures of $\mathrm{O}_{2} / \mathrm{CO}_{2}$," Fuel, vol. 84, no. 7-8, pp. 833-840, 2005.

[10] L. R. Radovic, "The mechanism of $\mathrm{CO}_{2}$ chemisorption on zigzag carbon active sites: A Computational Chemistry study," Carbon, vol. 43, no. 5, pp. 907-915, 2005.

[11] N. Chen and R. T. Yang, "Ab Initio molecular orbital study of the unified mechanism and pathways for gas-carbon reactions," Journal of Physical Chemistry A, vol. 102, no. 31, pp. 6348-6356, 1998.

[12] A. Montoya, F. Mondragón, and T. N. Truong, " $\mathrm{CO}_{2}$ adsorption on carbonaceous surfaces: A Combined Experimental and Theoretical Study," Carbon, vol. 41, no. 1, pp. 29-39, 2003.

[13] K. Sendt and B. S. Haynes, "Density functional study of the reaction of $\mathrm{O}_{2}$ with a single site on the zigzag edge of graphene," Proceedings of the Combustion Institute, vol. 33, no. 2, pp. 18511858, 2011.

[14] M. J. Frisch, G. W. Trucks, H. B. Schlegel et al., Gaussian 09, Revision B.01, Gaussian, Wallingford, Conn, USA, 2010. 

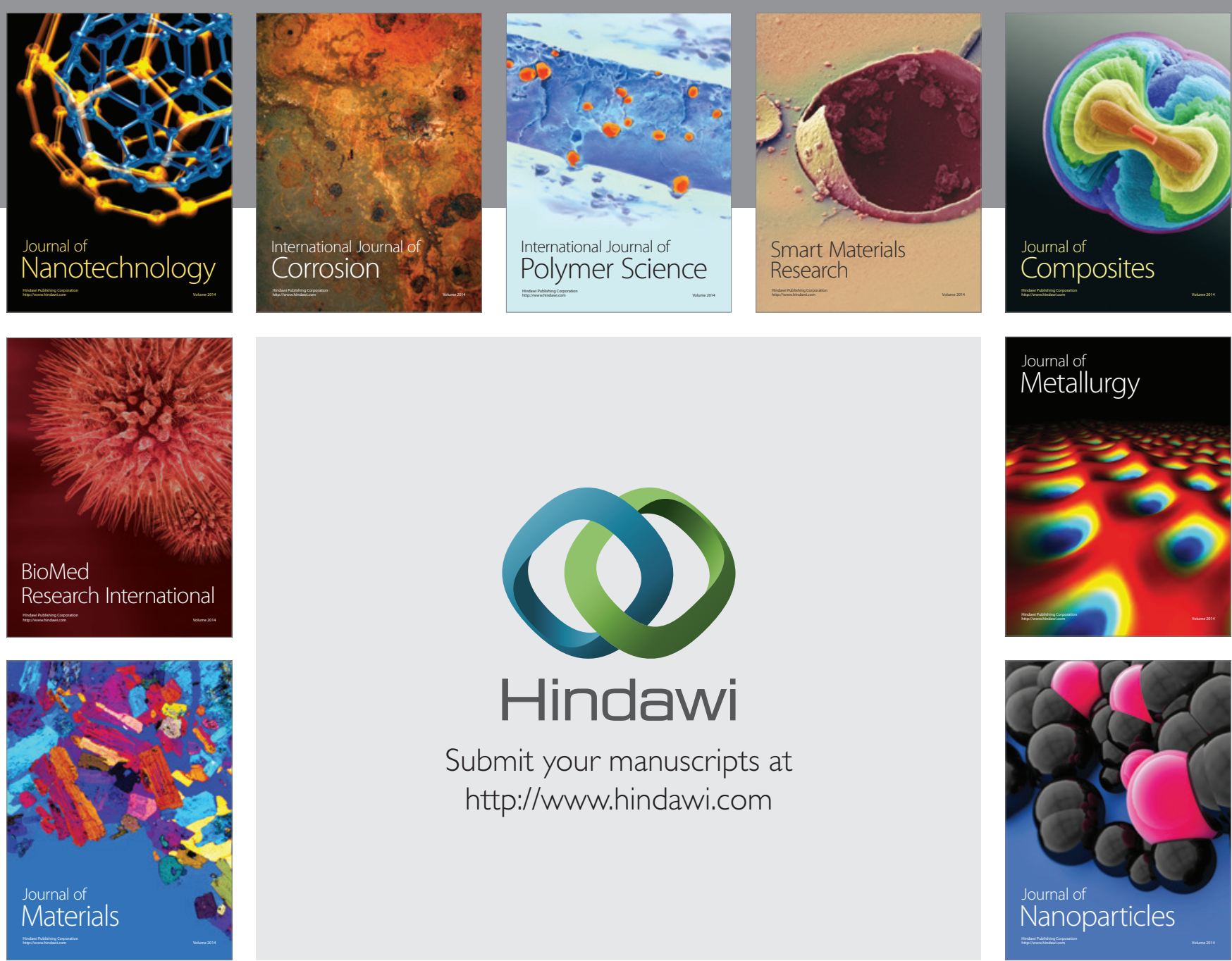

\section{Hindawi}

Submit your manuscripts at

http://www.hindawi.com

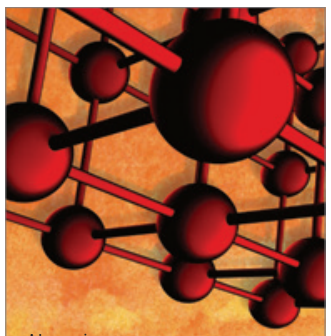

Materials Science and Engineering
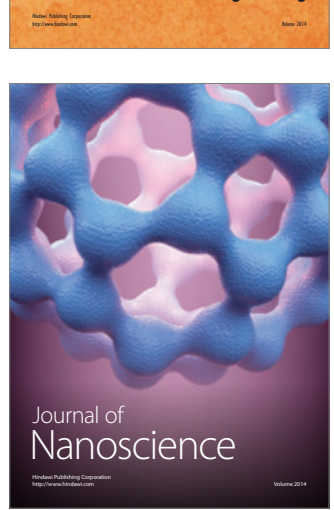
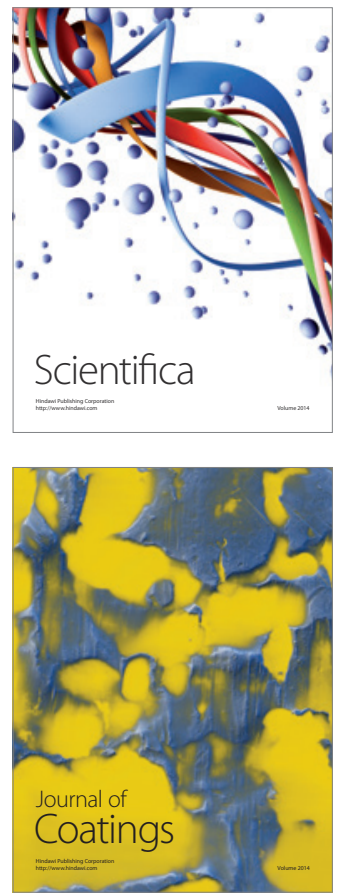
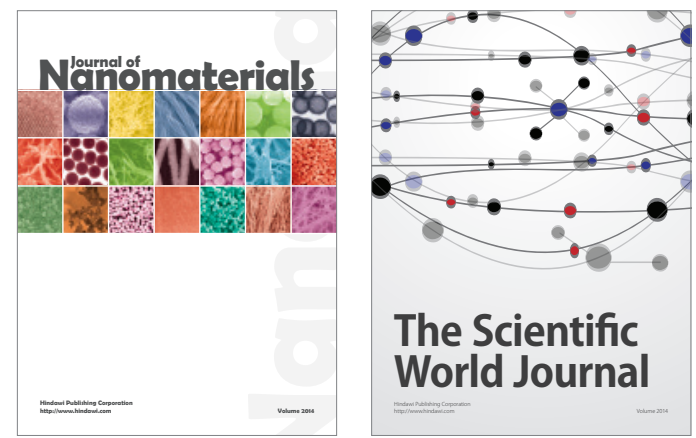

The Scientific World Journal
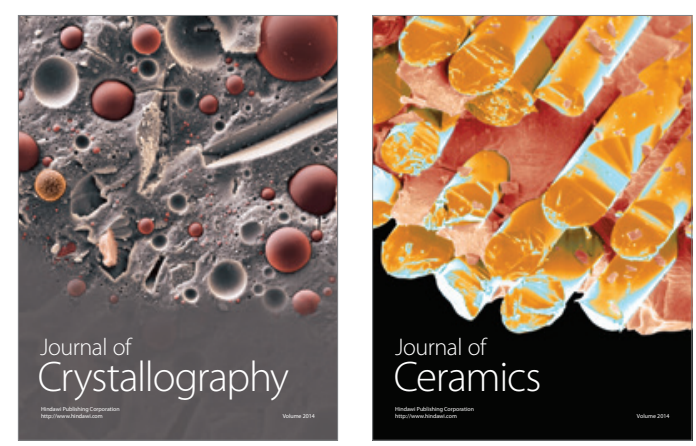
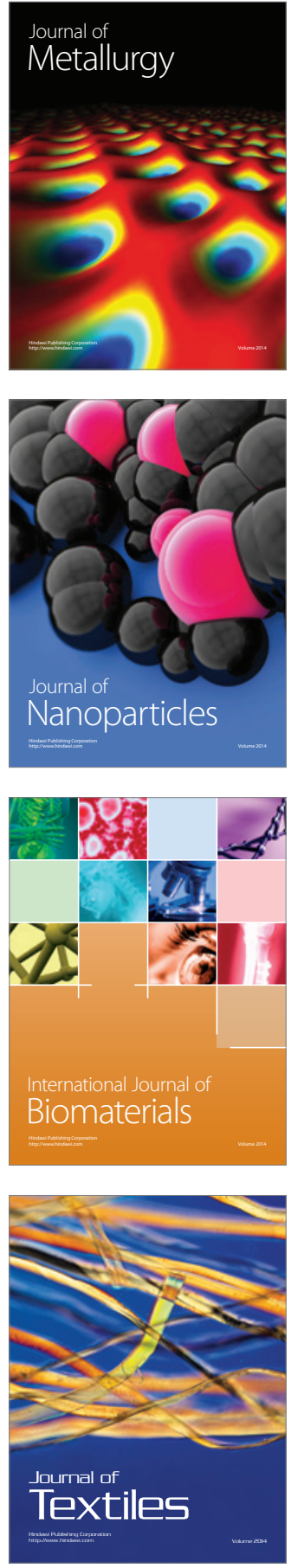